\title{
LA CASA Y LOS ENTORNOS DEL APRENDIZAJE EN LA COYUNTURA DE LA PANDEMIA
}

Fabio Jurado Valencia ${ }^{1}$

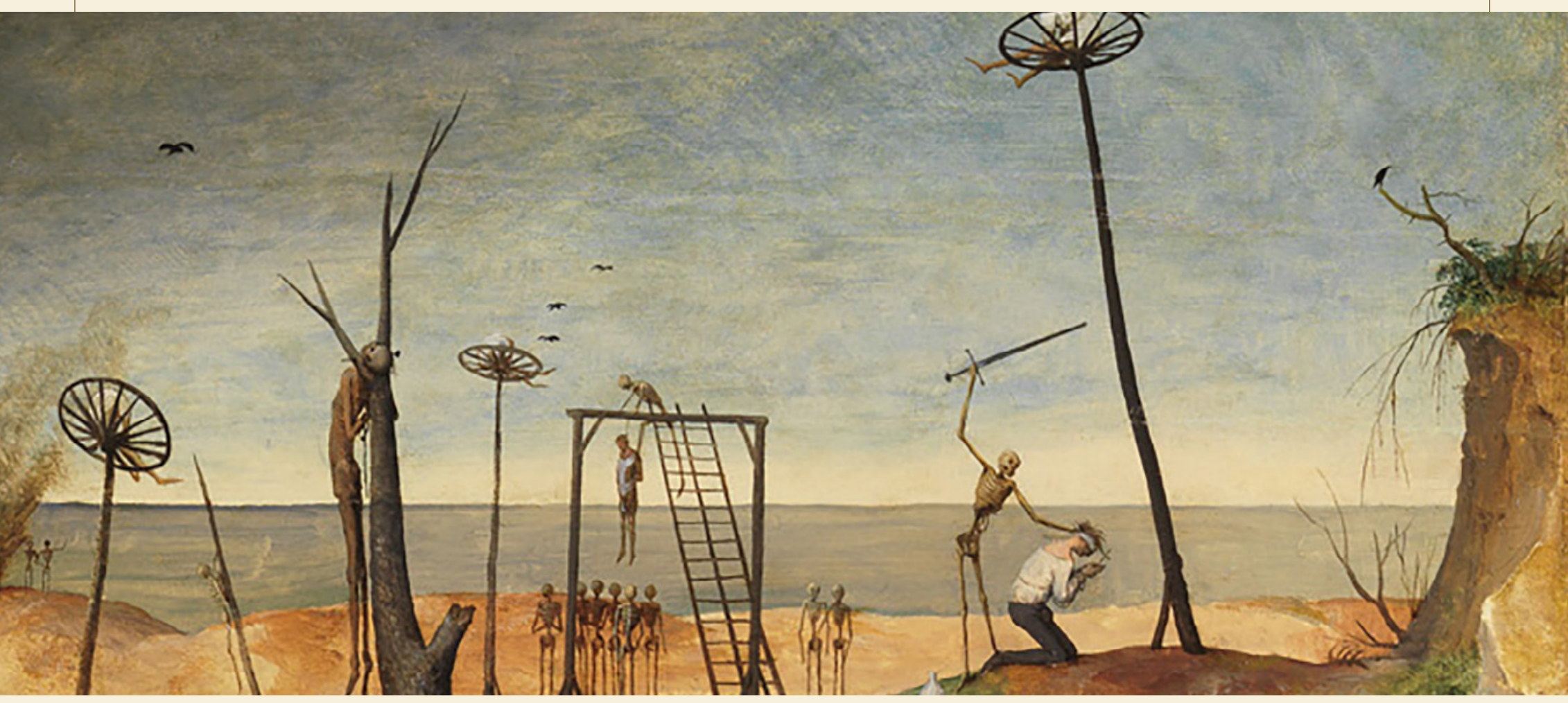

1 Doctor en literatura. Docente de la Universidad Nacional de Colombia. Miembro de la Red Colombiana para la Transformación de la Formación Docente en Lenguaje. Correo electrónico: fdjuradov@unal.edu.co ORCID https://orcid.org/0000-0001-6923-3652

Cómo citar: Jurado Valencia, F. (2020). La casa y los entornos del aprendizaje en la coyontura de la pandemia. Enunciación, 25(2, separata), XII-XVI. https://doi.org/10.14483/22486798.17020 

a educación no está asociada exclusivamente a la escuela, el colegio o la universidad; en el periodo del confinamiento familiar, por ejemplo, el discurso educativo está enhebrado en los lenguajes de quienes habitan la casa. Lenguajes y visiones de mundo, encarnados en las palabras, los gestos o las expresiones corporales, perviven con sus matices en la cotidianidad de la casa. Quienes habitan la casa saben algo distinto sobre la vida porque las experiencias de cada uno son diferentes; es decir, preguntas y argumentos sobre el fenómeno del confinamiento social circulan de diversos modos en el núcleo familiar. La conclusión vale no solo para quienes poseen las herramientas digitales de primera generación, sino también para quienes carecen de ellas, si bien las interacciones son distintas. El ser humano sin el deseo de aprender no existe; es, al contrario, acucioso y busca respuestas a sus dilemas.

Tanto en el pensamiento interior del niño de tres años, que tiene la oportunidad de aprender a leer historias a través de la escucha de la voz de quienes lo quieren, como de los jóvenes con sus irreverencias y controversias, es natural la diversidad de las percepciones y visiones sobre las cosas y los artefactos que ocupan la casa (reproducciones pictóricas, estatuillas, muebles, electrodomésticos, bombillos, espejos...), como poéticamente lo muestra Celso Román, en Las cosas de la casa (2019):

Una vieja canción dijo, desde hace muchos años, qué cosa eran los bombillos: calabacitos alumbradores.

Eran los frutos del totumo-luciérnaga, el iluminado de los árboles. Solo crecía en la cintura de la Tierra, donde el sol da todo el año, lugar que hoy los científicos identifican con el nombre de ecuador, pero que hace siglos era dominio de los incas, pueblo al que nos referimos al hablar de las chapas, precisamente porque no las usaban.

En los jardines del Inca, donde según la leyenda todo era de oro, estaban los árboles de totumo que producían los calabacitos alumbradores. Al contrario de lo que ocurre hoy día, en ese entonces su uso estaba limitado a la iluminación de los jardines sagrados, las habitaciones del soberano y los templos del Sol y de la Luna.

Thomas Alva Edison, un sabio que creía en la fantasía, oyó hablar alguna vez de los calabacitos alumbradores que los conquistadores creyeron de oro, y que precisamente destruyeron por no serlo. Ellos buscaban el metal precioso, no la luz, y por eso inventaron un adagio: "No todo lo que brilla es oro". Edison dijo que sería posible volver a hacerlos y se propuso inventárselos para así, al menos en parte, restituirle a la naturaleza algo de la belleza que la ambición del hombre había destruido... (p. 45)

Cuántos correlatos emergen en la conversación en casa a partir de la lectura de un libro como el de Román; cada núcleo semántico (calabacitos alumbradores, el totumo-luciérnaga, la cintura de la Tierra, ecuador, los incas, el oro, templos del Sol y de la Luna, Thomas Alva Edison, los conquistadores, la ambición del hombre) remite a una búsqueda en las bibliotecas virtuales, esto es, al viaje, estando en la casa, hacia espacios culturales que anteceden nuestro devenir. Tal conversación, mediada por los textos que aluden a los correlatos, hace posible la lectura crítica: el descubrimiento de las sustancias profundas del texto.

Con los dilemas y las preguntas sobre los artefactos de la casa se configuran interacciones, y en las interacciones despuntan los aprendizajes, aunque no sean nombrados en el aquí-ahora de la conversación; después aparecerán como chispas en el lenguaje mismo, en contextos de situación que activan lo que está guardado en la memoria; nadie aprende solo, se aprende con otros y, sobre todo, con el disentimiento y la duda: Es la escuela de la casa en el siglo XXI, la que busca la articulación con la escuela formal-institucional, la del foro y el balance en torno a lo aprendido y a lo 
desaprendido, si bien no siempre el puente que las articula es el más adecuado.

Se aprende pues en la casa, sobre la casa y sus entornos, de manera tácita y no necesariamente de modo unilateral; lo aprendido dependerá de los acervos culturales de cada grupo: los miembros de la familia, sea esta nuclear, monomarental, homoparental, extensa o mixta, aprenden escuchando, observando, tocando, leyendo y hablando, y no en una única dirección, como creer que los mayores les enseñan a los menores, pues los dilemas de estos últimos propician aprendizajes en los mayores; los menores, por cuanto actúan sin prejuicios, propenden con más agilidad hacia la imaginación y la creatividad; de allí los asombros cuando observamos a niños dibujando, usando un instrumento musical, desbaratando un juguete y estructurando otro, accediendo a las lógicas de los juegos virtuales, escribiendo, dibujando, escuchando y desarrollando recetas en la cocina... (figura 1).

Así entonces aunque la familia considere que la institución académica es el lugar para aprender, y por eso paga o reclama al Estado por proporcionar los espacios disponibles, la coyuntura del aislamiento físico del mundo de afuera ha sido propicio para reconocer que la escuela como institución está ahora en intersección con la escuela de la casa; y el mundo de afuera está en el mundo de adentro a través de las herramientas digitales y de los libros. Estamos presenciando la fusión de las dos escuelas, aunque no de manera equilibrada, porque pertenecemos a una sociedad muy desigual; esta relación desigual da lugar inevitablemente a la incertidumbre, dado que no sabemos lo que ocurre dentro de la vivienda de los vecinos y de la gente más
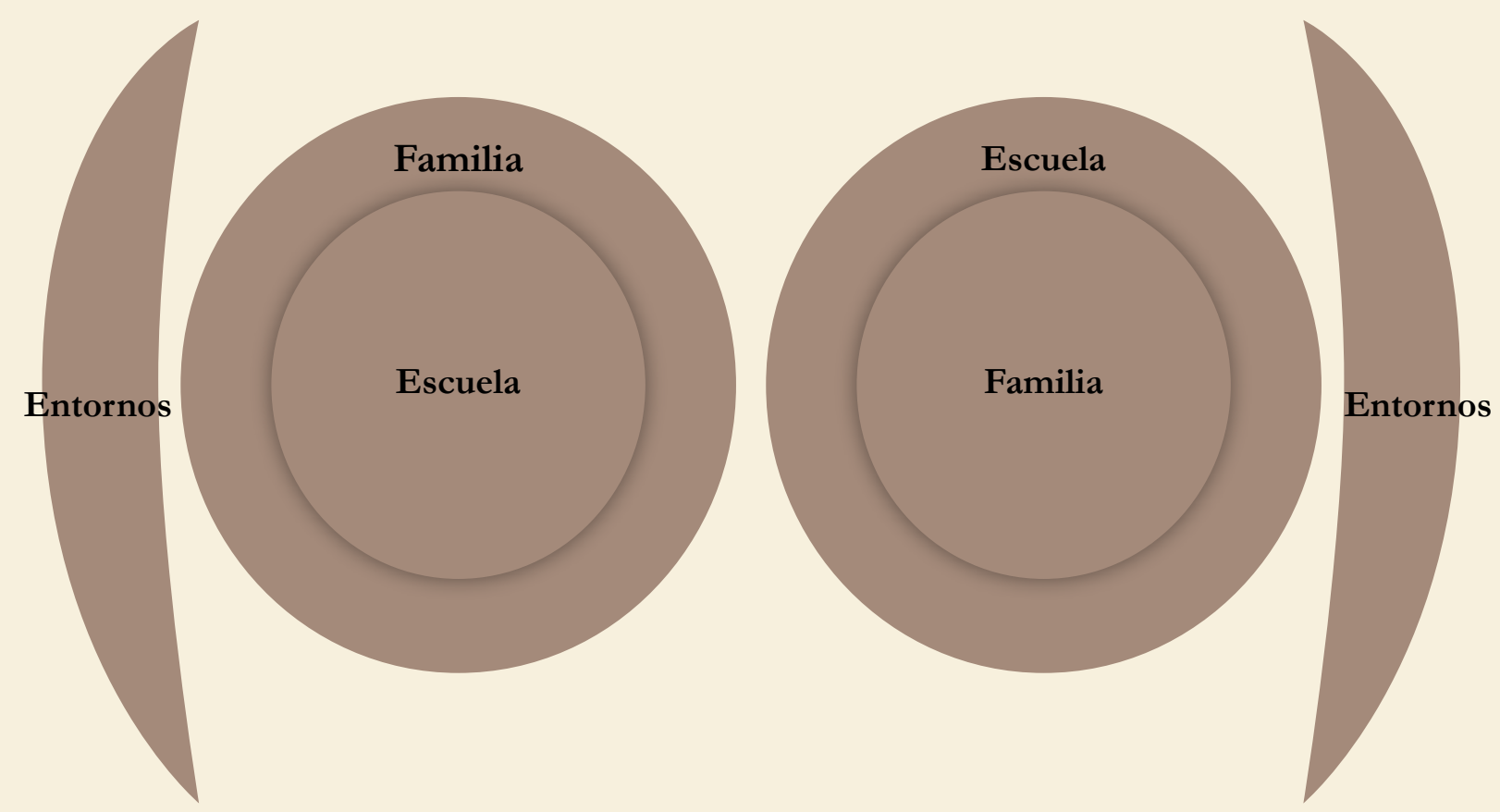

Figura 1. La familia en la escuela o la escuela en la familia

Fuente: elaboración propia 
pobre; ha sido brusca tal conjunción porque a través del único computador de la casa y la estrechez espacial, cuando es el caso, se han puesto al descubierto tensiones familiares que son inevitables por las frustraciones (figura 2).

¿Aprenderán más en la casa (pedagogía local) que en la escuela (pedagogía oficial) (Bernstein, 1990), porque ahora sí a padres y madres, o cabezas de familia, les preocupa la suspensión de la escuela formal y se empeñan en trabajar juntos? En el caso de las clases sociales medias -media baja, media media y media alta-, ¿cómo se turnan los miembros de la familia para usar el computador de mesa, tan necesario para el teletrabajo y para la educación remota? Todos en la familia tienen teléfono móvil, pero no todos tienen el computador portátil o de mesa, y esto es más notorio en los sectores pobres.
Asimismo, es necesario saber si la escuela tradicional se ha trasladado tal cual como es (el exceso de tareas, la atomización de las asignaturas y sus contenidos, el extravío del horizonte de los aprendizajes...) al espacio de la casa y, en consecuencia, ha chocado con la flexibilidad de la pedagogía de la casa o, al contrario, la intersección de una y otra pedagogía ha posibilitado la ampliación del capital cultural de todos los que habitan la casa.

Las regulaciones de la escuela tradicional condujeron, en efecto, al colapso en la primera etapa del confinamiento, porque el paso de la educación presencial a la remota o virtual fue abrupto: cada docente envía talleres y guías con distinto perfil pedagógico (con diseño propio o ajeno); progresivamente el grupo familiar, abrumado por las rutinas escolares en casa, se fue fatigando, pues afectaba también la cotidianidad y los

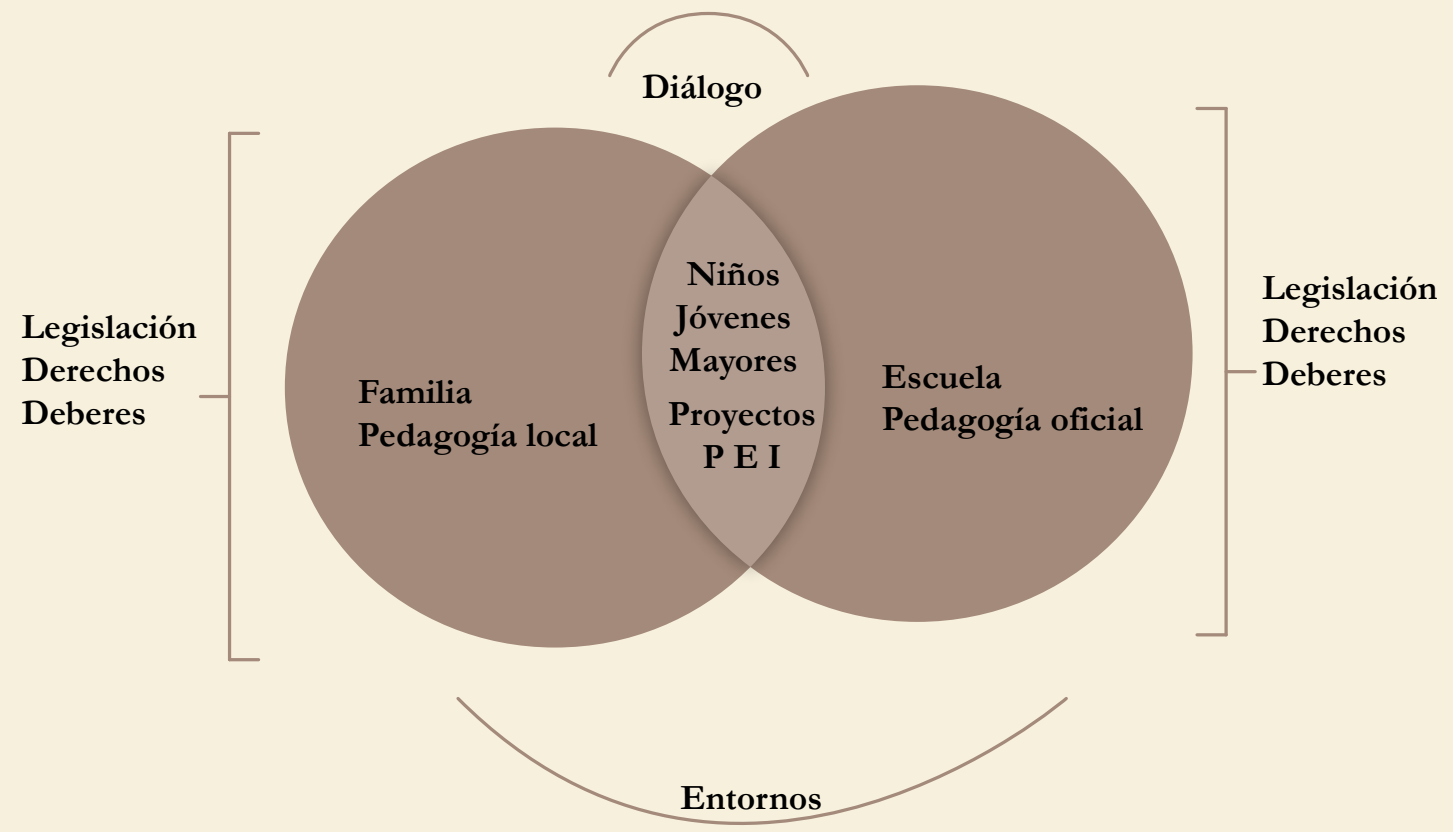

Figura 2. La intersección pedagógica a partir de los proyectos

Fuente: elaboración propia. 
compromisos laborales. En estos casos, la escuela institucional y la escuela familiar no convergen, por el carácter artificial de la primera (no todas por supuesto), aunque haya casos en los que la segunda le reclame a la primera sus rutinas. ¿Flexibilidad o verticalidad, en la educación del confinamiento?

Según declaran los docentes del sector público (conversatorios virtuales de la Red Colombiana para la Transformación de la Formación Docente en Lenguaje, realizados en 2020), el aplicativo WhatsApp se convirtió en el medio más recurrente para recibir y enviar tareas, pero también para orientar el desarrollo de proyectos en la casa, así hubiese que subirse a los árboles para buscar la señal en los contextos rurales; a pesar de las limitaciones, la escuela continuó su marcha, ahora de manera remota, con aprendizajes de docentes, estudiantes y familias en el mismo proceso: diseñando actividades novedosas, potenciando la creatividad.

La pedagogía por proyectos está insinuada en el Decreto 1860 de 1994, y quienes no habían incursionado en este enfoque ahora lo han intentado y ojalá permanezca cuando se retorne a la escuela institucional, sin la pandemia; el trabajo con proyectos es sin duda la ruta principal para que niños, jóvenes y personas mayores, con los docentes, asignen sentido al acto de aprender. Cuántos proyectos pueden surgir al preguntarnos por el origen y las características de las cosas que ocupan la casa o de las cosas que observamos a través de las ventanas del apartamento o de la habitación, en este mundo que ahora parece estático por el confinamiento: aves que no habíamos visto; insectos raros; cielos despejados y azules, sin el esmog; diversos verdes de los árboles, unos anchos y otros largos; flores que se asoman entre las rejas de los jardines; hombres con carretas seleccionando las basuras para el reciclaje y, al terminar el día, el espectáculo del cine con el horizonte de los temas acordados en la casa: ciclos de películas sobre las epidemias, sobre biografías de artistas y científicos, sobre cómo Europa y Asia despegaron socialmente, respetando los pactos, después de dos guerras mundiales, y también el wéstern norteamericano con sus anclajes históricos.

No ha habido otro momento de tan intensa reflexión y de tantas preguntas como en esta coyuntura; preguntas sobre el estado medioambiental del planeta, sobre los orígenes del racismo, la exclusión y los asesinatos de líderes sociales, sobre la alimentación humana y animal, sobre las mujeres que gobiernan un país o una ciudad, sobre los comportamientos indolentes o dolientes de los gobernantes y los parlamentarios, sobre las redes sociales, sobre el modelo económico vigente y sus paradojas, sobre las vacunas y el diálogo de las profesiones en la búsqueda de soluciones (biotecnología; medicina epidemiológica; química de la enfermedad; ingeniería de sistemas; estadística de la salubridad; comunicación impresa, oral y audiovisual; sociología e historia de las pandemias; psicología familiar y hospitalaria...).

Cada campo disciplinar proporciona de manera integrada insumos para la pedagogía por proyectos en la escuela institucional y en la escuela de la casa, ahora en relación dialogante; ello presupone asumir la lectura y la escritura como prácticas transversales que solventan el desarrollo del pensamiento crítico-analítico, necesario para saber prevenir y saber tomar decisiones, y lo más importante: posibilitar el equilibrio emocional y afectivo en situaciones de desesperanza y en periodos de crisis, como está ocurriendo en el año bisiesto de 2020.

\section{Referencias bibliográficas}

Bernstein, B. (1990). La construcción social del discurso pedagógico. Bogotá: El Griot.

Román, C. (2019). Las cosas de la casa. Bogotá: Panamericana.

\section{(c) (1) $(9)$}

